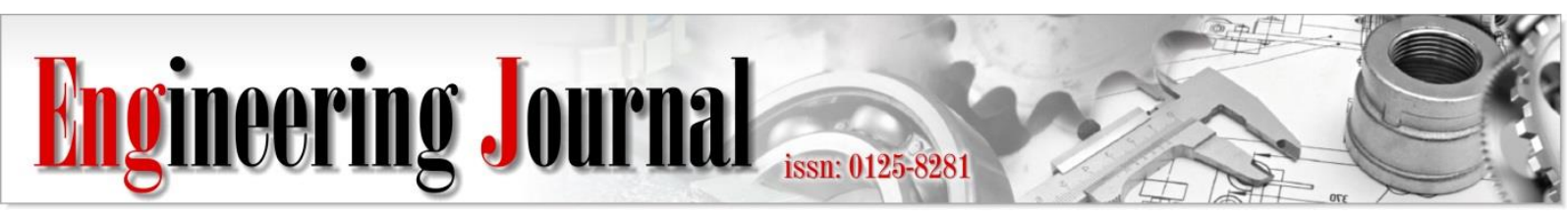

Article

\title{
Optimization for Biodiesel Production by Transesterification with Electric fields
}

\author{
Thibordin Sangsawang*, Nirat Rongrat, and Aphishat Yothayuth \\ Department of Mechanical Engineering, Faculty of Engineering and Industrial Technology, Silpakorn \\ University, Nakhon Pathom 73000 \\ Email: *Sangsawang_t@su.ac.th (Corresponding Author)
}

\begin{abstract}
The objective of this research is to study optimization for biodiesel production from transesterification with electric fields. The catalyst in this reaction is potassium hydroxide $(\mathrm{KOH})$ at $1 \%$ weight (wt). The molar ratio is 6:1. Two factors at three levels are considered using the response surface method. The first factor, the intensity of the electric field, is set at 85 volts/centimeter $(\mathrm{V} / \mathrm{cm}), 170 \mathrm{~V} / \mathrm{cm}$, and $255 \mathrm{~V} / \mathrm{cm}$. The second factor, the retention time of the electric fields, is set at 2 minutes ( $\mathrm{min}$ ), $6 \mathrm{~min}$, and $10 \mathrm{~min}$. In the experiments, the best yields are produced from an electric fields intensity of $85 \mathrm{~V} / \mathrm{cm}$, with the electric field's retention time of $2 \mathrm{~min}$. The calculated and experimental results are $98.26 \%$ and $98.41 \%$, respectively.
\end{abstract}

Keywords: Biodiesel, transesterification, response surface methodology, electric fields.

ENGINEERING JOURNAL Volume 25 Issue 2

Received 7 February 2020

Accepted 25 November 2020

Published 28 February 2021

Online at https://engj.org/

DOI:10.4186/ej.2021.25.2.261 


\section{Introduction}

With the current situation of global warming and unstable fuel prices, the Thai government has accelerated the search for alternative sources of environmentally friendly energy, especially biodiesel from plants. Biodiesel, which is a source of sustainable and clean energy, has begun to gain worldwide and growing attention, and is evolving into a diesel fuel substitute derived from ecological sources. Biodiesel from vegetable oil, animal fats, or waste cooking oils is generally popular for use as a direct substitute for diesel fuel or is partially mixed with diesel fuel. Ma and Hanna [1] reviewed the biodiesel production process. They found four method to produce biodiesel from vegetable oil and animal fat. The first method was direct use and blending. The method could be used with any vegetable oil and fat. However, gum and viscosity of oil caused the lower performance and more maintenance cost of engine. The second method was microemulsions. This method made the lower viscosity of oil and fat with solvent such as methanol, ethanol or butane. The third method was thermal cracking or pyrolysis. This method was the conversion of one substance into another by heat with catalyst. The heat involved in the cleavage of chemical bond to small molecules with no oxygen or air environments. The materials could be vegetable oils, animal fats or natural fatty acids. The final method was transesterification or alcoholysis. It was the reaction of oil or fat with an alcohol to produce ester and glycerol. A catalyst was used to improve the reaction rate and yield. The alkali base as $\mathrm{NaOH}$ and $\mathrm{KOH}$ were the catalyst in this reaction.

The most popular biodiesel is made from palm oil, coconut oil, or waste cooking oils [2-3]. As mentioned earlier, biodiesel seemed to be produced from various vegetable oils and fats. All of them are edible sources. Rezania et al. [4] investigated the transesterification from non-edible oil such as Jatropha, algae, waste cooling oil, macaw oil, karanja oil, waste animal fats etc. They also considered the environmental effects and by-product. They found the properties of biodiesel from non-edible oil had similar fuel properties with ASTM D6751 and EN14214 standard. The selection feedstock and catalyst type could reduce the production cost. The catalyst with no effect to the environment was recommended. As a prescribed fuel, biodiesel involves a transesterification process which produces esters and glycerin, using alcohol as a reactant and sodium hydroxide as a catalyst [5-6].

This study is on the production of biodiesel for higher yields. In their study, Verma and Sharma [7] explored the effects of parameters in biodiesel production using a transesterification reaction. They found the parameters that affected yields were reaction temperature and catalyst concentration. They concluded that a catalyst concentration of $1 \%$, molar ratio of methanol to oil are $6-12: 1$, temperature of $50-60^{\circ} \mathrm{C}$, gave the highest biodiesel yield in the lowest possible time and with the lowest increase in temperature to catalyze the reaction. Stromberg et al. [8] studied the efficiency of phase separation for biodiesel quality and blending. The results showed that the factor affecting phase separation efficiency was an emulsifier that came from the oxidation reaction between oil and moisture. This oxidation caused the formation of shortchain fatty acids and increased the phase separation.

Ahmad et al. [9] studied the parameters that affected the rate of biodiesel production from a transesterification reaction. They used the response surface method (RSM) to predict optimum conditions. The optimum parameters were a temperature of $59^{\circ} \mathrm{C}$, retention time of $33 \mathrm{~min}$, a catalyst of $0.51 \% \mathrm{wt}$, and a molar ratio of 5.9:1. Tan et al. [10] used response surface method to explore the biodiesel production from used cooking oil. They used fusion waste chicken and fish bones as catalyst. There were three variables, catalyst concentration, temperature and time of reaction. The RSM showed the optimal operating condition was catalyst concentration of $1.98 \%, 65^{\circ} \mathrm{C}$ and 1.54 hours. The biodiesel properties were in acceptable ranges according to the ASTM D6571.

Nonthawan et al. [11] and Boodkot and Khanthong [12] studied biodiesel production from the transesterification reaction with an electric fields. They used vegetable oil as the raw material for production, with a mass ratio of palm oil to methanol of 6:1. The catalyst was sodium hydroxide $(\mathrm{NaOH})$ at the ratio of $1 \%$ by weight of oil. The electric fields generator provided $15 \mathrm{kV}$, $30 \mathrm{~mA}$ output voltage, two pairs of electrodes with the distance between the two electrodes of $3 \mathrm{~cm}, 4 \mathrm{~cm}$, and 5 $\mathrm{cm}$, and a reaction time of 30 minutes. The results showed that the highest yield of biodiesel was $91.84 \%$ with the electrodes spaced $3 \mathrm{~cm}$ apart. Moreover, Sangsawang and Phetsuwan [13] produced biodiesel from animal fat collected from swine farms in Nakhon Pathom, Thailand. Triglyceride in swine fat was transformed into methyl ester then into biodiesel from the transesterification process within 20 minutes. It was also possible to produce biodiesel from used palm oil. Wang et al. [14], in studying the effect of electric fields on an ethanol droplet in oil, observed that the electric fields created the break-up phenomenon of the ethanol in the oil. The droplet sizes were smaller and well mixed with oil under electric fields. The situation supplied good reaction conditions for the transesterification reaction. Sangsawang et al. [15] studied the effect of methanol and ethanol on the yield of biodiesel production from transesterification with electric fields from two pairs of electrodes. They found that the disadvantage of ethanol was moisture that caused a saponification reaction.

Previous studies have shown the possibility of using electric fields to produce biodiesel. However, the applicable biodiesel production parameters under electric fields are still unknown. The current research studied the effects of retention time and electric fields on biodiesel production using RSM. The response surface methodology (RSM) is a method that can be applied to various developments, such as developing production formulas, improve the production process, and define a suitable point from the data obtained from the experiment. Therefore, this research has applied RSM to 
find the optimum conditions for biodiesel production under the conditions of electric fields.

\section{Materials and Methodology}

\subsection{Equipment and Materials}

Nutaman and Tiansuwan [16], Ngammuang et al. [17,] and Thippaha et al. [18] used electric fields from barrier discharge electrodes to accelerate the transesterification reaction in biodiesel production. They found that the barrier discharge reduced the electrical power and was safer than the conventional method [11-13]. The conventional method that mentioned used two pairs of electrodes. The anodes and cathodes were placed in the vegetable oil. They used much higher voltage of electricity. It caused un-safety conditions.

In the current research, the reactor uses barrier discharge electrodes, each of which comprises a copper cathode wrapped around a glass tube, as shown in Fig. 1. The aluminum anode is placed at the core of the glass tube to avoid an occurrence arc. The AC power supply is supplied to the variable voltage transformer at $220 \mathrm{~V}$ and the electric fields retention time is $2 \mathrm{~min}, 6 \mathrm{~min}$, and 10 min, respectively.

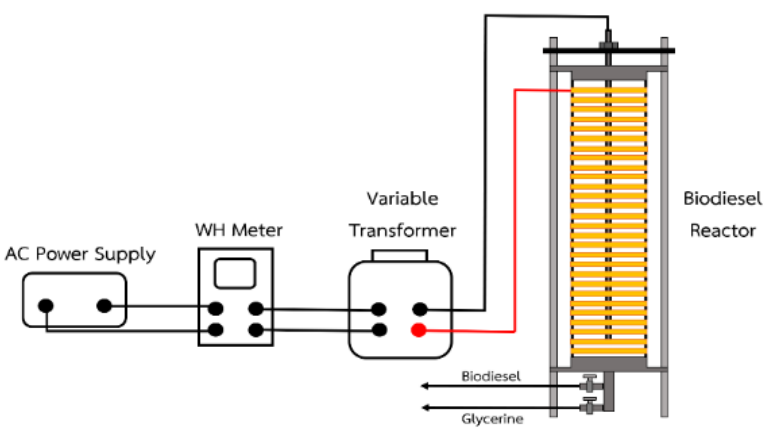

Fig. 1. Experiment apparatus.

In this experiment, the vegetable oil is refined palm olein from Olein Co. Ltd. The properties of palm olein are presented in the Table 1. The palm olein obtained by the fraction of palm oil after crystallization. Palm olein consists of triglyceride higher than $99 \%$ wt. The major fatty acid in palm olein are palmitic and oleic acid.

Table 1. Composition of palm olein [19]

\begin{tabular}{lc}
\hline Fatty acid & $(\mathbf{\%} \mathbf{w t})$ \\
\hline Palmitic acid & 39.8 \\
Stearic acid & 4.4 \\
Oleic acid & 42.5 \\
Linoleic acid & 11.2 \\
Others & 2.1 \\
\hline
\end{tabular}

Methanol is at $100 \%$ concentration for the molar ratio of methanol to oil are 6:1. The catalyst is $\mathrm{KOH}$ at $1 \% \mathrm{wt}$ which is more easily found locally. The initial temperature of the reaction is $65^{\circ} \mathrm{C}$ as presented in the Table 2 .
Table 2. Experiments conditions.

\begin{tabular}{|l|l|}
\hline Condition & value \\
\hline Temperature & $65^{\circ} \mathrm{C}$ \\
\hline Catalyst & $\mathrm{KOH} 1 \%$ wt of palm olein \\
\hline Molar ratio & $6: 1$ \\
\hline Time & 2 hours \\
\hline Alcohol & $100 \%$ methanol \\
\hline
\end{tabular}

\subsection{Methodology}

The biodiesel production with electric fields start with mix methanol and catalysts into palm olein oil at an initial temperature of $65^{\circ} \mathrm{C}$. The process begins with an electric fields intensity (EFI) of $85 \mathrm{~V} / \mathrm{cm}, 170 \mathrm{~V} / \mathrm{cm}$, and 255 $\mathrm{V} / \mathrm{cm}$ and a retention time of $2 \mathrm{~min}, 6 \mathrm{~min}$, and $10 \mathrm{~min}$. Biodiesel and glycerin are then separated for two hours in the reactor, after which biodiesel purification proceeds. There is no stirrer in this process because the electric fields can reduce the surface tension of palm oil according to the study of Wang et al. [14].

All experiments are tested and compared with biodiesel production from the conventional reaction. This reaction uses a hot plate to heat the palm olein oil from the ambient temperature to $65^{\circ} \mathrm{C}$. The methanol and finely catalyst mixed and feed into the palm olein oil with the temperature maintained at $65^{\circ} \mathrm{C}$. The heater is used to maintain the temperature for the retention time of time of $2 \mathrm{~min}, 6 \mathrm{~min}$, and $10 \mathrm{~min}$ respectively. The stirrer is operated for well mixing between methanol and palm olein oil.

Biodiesel from both reaction are treated by hot water $\left(60^{\circ} \mathrm{C}\right)$ twice. The biodiesel yield can be defined from Eq. (1):

$$
\text { Yield } \%=\frac{\text { Weight of Biodiesel }}{\text { Weight of Palm Oil }} \times 100 \%
$$

\subsection{Response Surface Method}

In the experiment design for biodiesel production using the RSM, the two parameters are electric fields intensity (EFI) and retention time, as listed in Table 3. The experiment design followed the Box - Behnken design. These parameters are divided into three standardized levels and presented in the coding form of $-1,0$, and +1 . In this $3^{2}$ factorial design, the total number of experiments is calculated as follows: $3^{2}=9$ designing points; each point has two experiments; therefore, 18 experiments are conducted in total. The actual value and coding form are presented in Table 3. The regression analysis is presented in Eq. (2):

$$
Y=\beta_{0}+\sum_{i=1}^{N} \beta_{i} X_{i}+\sum_{i=1}^{N} \beta_{i i} X_{i}^{2}+\sum_{i=1 i<j i=2}^{N-1} \sum_{i j}^{N} \beta_{i j} X_{i} x_{j}
$$

where $\mathrm{y}$ is the $\%$ yield of biodiesel, and $\beta_{\mathrm{i}}, \beta_{\mathrm{ii}}$, and $\beta_{\mathrm{ij}}$ are the coefficients calculated from the regression analysis. 
This data from the experiments will be analyzed the RSM by MINITAB v.18.

Table 3. Levels and ranges of independent factors.

\begin{tabular}{|l|c|c|c|c|}
\hline \multirow{2}{*}{ Parameters } & \multirow{2}{*}{ Factors } & \multicolumn{3}{|c|}{ Level } \\
\cline { 3 - 5 } & & $\mathbf{- 1}$ & $\mathbf{0}$ & $+\mathbf{1}$ \\
\hline EFI (V/cm) & $\mathrm{X}_{1}$ & 85 & 170 & 255 \\
\hline Time (min) & $\mathrm{X}_{2}$ & 2 & 6 & 10 \\
\hline
\end{tabular}

\section{Results and Discussion}

Figure 2 shows the characteristics of the biodiesel reaction rate. Figure 2a presents the condition with an EFI of $85 \mathrm{~V} / \mathrm{cm}$. For a retention time of $2 \mathrm{~min}$, it is clear that this condition provides the highest reaction rate of biodiesel production compared to other levels of EFI and matches the conventional transesterification reaction. In the experiments, this condition provides the highest percentage yield of over $98 \%$, while the lowest reaction rate is from the conventional reaction. Figure $2 \mathrm{~b}$ presents the biodiesel reaction rate with an EFI for 6 min, with EFIs for $85 \mathrm{~V} / \mathrm{cm}$ and $170 \mathrm{~V} / \mathrm{cm}$ providing a higher yield than that of an EFI for $255 \mathrm{~V} / \mathrm{cm}$ and the conventional reaction.

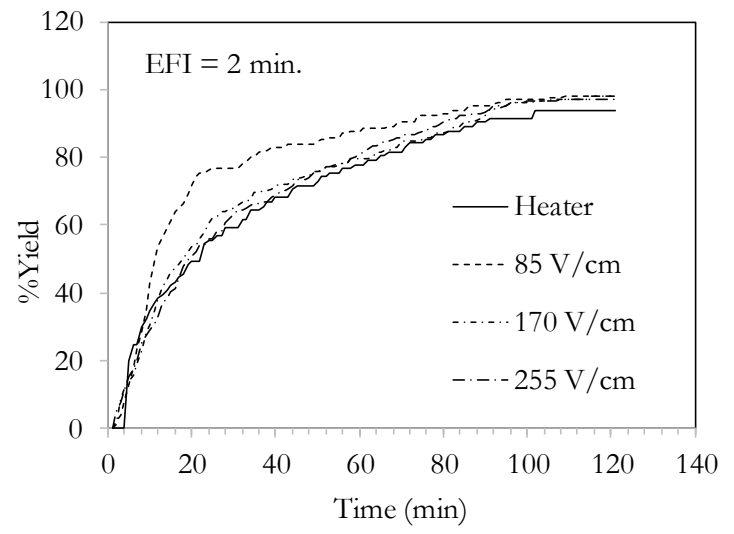

a. Production rate with electric fields intensity (EFI) of $2 \mathrm{~min}$

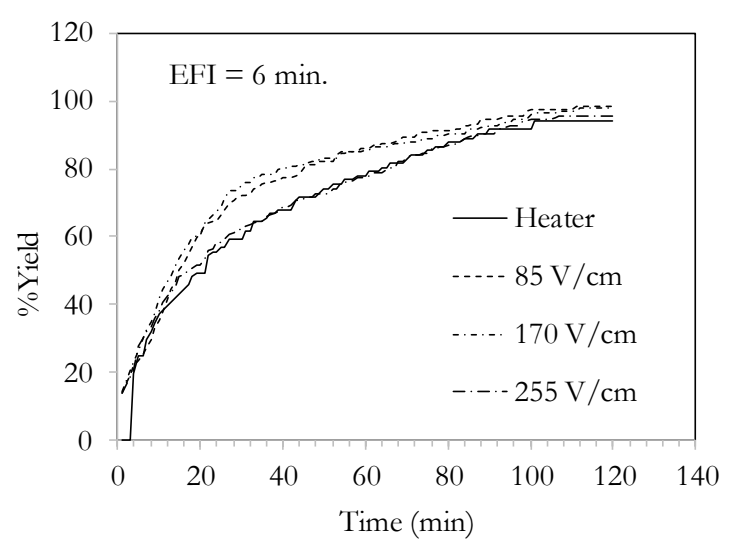

b. Production rate with electric fields intensity (EFI) of $6 \mathrm{~min}$.

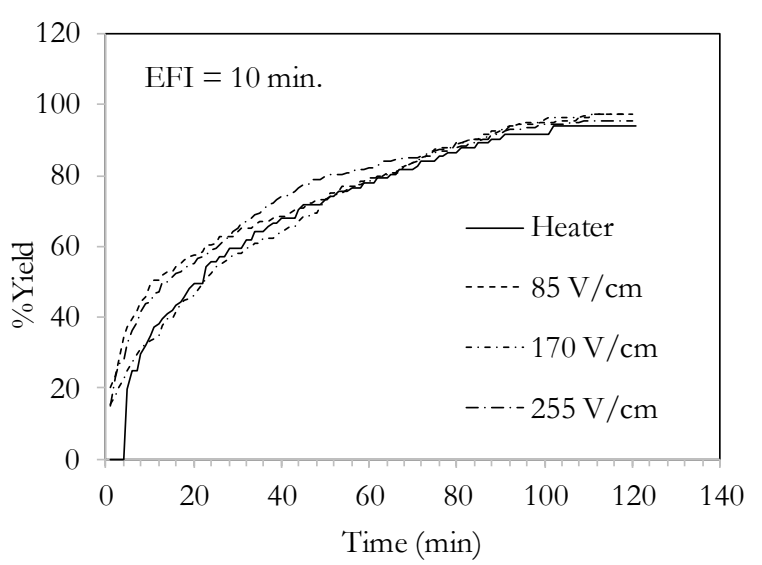

c. Production rate with electric fields intensity (EFI) of $10 \mathrm{~min}$.

Fig. 2. Biodiesel production rate with electric fields intensity (EFI) and retention time.

Figure 2c displays a biodiesel reaction rate for an EFI of $10 \mathrm{~min}$; therefore, for this condition, EFI seems to be unnecessary for the reaction. The rate of production from EFI is slightly higher than from the conventional reaction.

In Fig. 2, it is clear that EFI affects the transesterification, in accordance with the study of Wang et al. [11], with EFI forming the break-up phenomenon of alcohol in the oil. The smaller size of the ethanol droplets allows better contact with the palm olein oil, resulting in better reactions.

The transesterification is a reversible reaction [1]. As can be seen in Fig. 2b and 2c, the reaction rate is slower than Fig. 2a. This might be caused by the reaction in Fig. $2 \mathrm{a}$ is completed. There is no methanol remained in the product. The reaction in Fig. $2 \mathrm{~b}$ and $2 \mathrm{c}$ are slower and allow the product to reversed back to the reactants.

However, the reaction of biodiesel production from the electric fields can produce the best productivity in both shorter times. Figure 2 show the faster rate of reaction than the conventional method. The transesterification with the electric fields present the complete reaction within $100 \mathrm{~min}$ while the conventional method, the reaction is completed in $120 \mathrm{~min}$ or more.

\subsection{Regression Model}

These experiments have nine designing points, with each point having two experiments, as mentioned in Section 2.3. The orthogonal form is presented in Table 4.

When considering the $3^{2}$ factorial design as shown in Table 3. There are 9 test points, two repeats each for a total of 18 experiments as mentioned in section 2.3. The values of $\mathrm{X}_{1}$ and $\mathrm{X}_{2}$ will be changed to the actual values in the calculation according to Eq. (2). For the orthogonal design, the constant of $\mathrm{X}_{1}^{2}, \mathrm{X}_{2}^{2}$ and $\mathrm{X}_{1} \mathrm{X}_{2}$ must be in Table 4. 
Table 4. Orthogonal form and response vector $(\mathrm{Y})$.

\begin{tabular}{|c|c|c|c|c|c|c|c|c|c|}
\hline Point & $\beta_{0}$ & $\mathrm{X}_{1}$ & $\mathrm{X}_{2}$ & $\mathrm{x}_{1}^{2}$ & $\mathrm{X}_{2}^{2}$ & $\mathrm{X}_{1} * \mathrm{X}_{2}$ & & & \\
\hline \multirow[t]{2}{*}{1} & 1 & -1 & -1 & $1 / 3$ & $1 / 3$ & 1 & & 98.10 & Y11 \\
\hline & 1 & -1 & -1 & $1 / 3$ & $1 / 3$ & 1 & & 98.41 & Y12 \\
\hline \multirow[t]{2}{*}{2} & 1 & 0 & -1 & $-2 / 3$ & $1 / 3$ & 0 & & 96.70 & Y21 \\
\hline & 1 & 0 & -1 & $-2 / 3$ & $1 / 3$ & 0 & & 98.96 & Y22 \\
\hline \multirow[t]{2}{*}{3} & 1 & 1 & -1 & $1 / 3$ & $1 / 3$ & -1 & & 96.50 & Y31 \\
\hline & 1 & 1 & -1 & $1 / 3$ & $1 / 3$ & -1 & & 98.03 & Y32 \\
\hline \multirow[t]{2}{*}{4} & 1 & -1 & 0 & $1 / 3$ & $1 / 3$ & 0 & & 97.78 & Y41 \\
\hline & 1 & -1 & 0 & $1 / 3$ & $-2 / 3$ & 0 & & 98.53 & Y42 \\
\hline \multirow[t]{2}{*}{5} & 1 & 0 & 0 & $-2 / 3$ & $-2 / 3$ & 0 & & 96.81 & Y51 \\
\hline & 1 & 0 & 0 & $-2 / 3$ & $-2 / 3$ & 0 & $\mathrm{Y}=$ & 98.57 & Y52 \\
\hline \multirow[t]{2}{*}{6} & 1 & 1 & 0 & $1 / 3$ & $-2 / 3$ & 0 & & 93.14 & Y61 \\
\hline & 1 & 1 & 0 & $1 / 3$ & $-2 / 3$ & 0 & & 98.10 & Y62 \\
\hline \multirow[t]{2}{*}{7} & 1 & -1 & 1 & $1 / 3$ & $-2 / 3$ & -1 & & 96.03 & Y71 \\
\hline & 1 & -1 & 1 & $1 / 3$ & $1 / 3$ & -1 & & 98.76 & Y72 \\
\hline \multirow[t]{2}{*}{8} & 1 & 0 & 1 & $-2 / 3$ & $1 / 3$ & 0 & & 96.28 & Y81 \\
\hline & 1 & 0 & 1 & $-2 / 3$ & $1 / 3$ & 0 & & 98.75 & Y82 \\
\hline \multirow[t]{2}{*}{9} & 1 & 1 & 1 & $1 / 3$ & $1 / 3$ & 1 & & 97.46 & Y91 \\
\hline & 1 & 1 & 1 & $1 / 3$ & $1 / 3$ & 1 & & 98.51 & Y92 \\
\hline
\end{tabular}

where $\beta_{0}$ is presented in Eq. (2). The constants of $X_{1}$ and $\mathrm{X}_{2}$ represent the level of EFI and time in Table 3 respectively.

The design metrics are presented in Table 4, with Yij representing the \%yield of biodiesel from the experiment. The constant $\beta_{0}$ must be adjusted into orthogonal form. The quadratic model is used in the regression analysis as mentioned in previous studied. [9-10]. The predicted values of biodiesel yields (Y) are calculated using regression model base on two factors, three levels. The predict quadratic regression model is based on analysis of variance (ANOVA) is expressed as Eq. (3);

$$
\begin{aligned}
\mathrm{Y}= & 99.263+0.00345 \mathrm{X}_{1}+0.5583 \mathrm{X}_{2} \\
& +0.000038 \mathrm{X}_{1}{ }^{2}+0.0395 \mathrm{X}_{2}^{2} \\
& +0.000646 \mathrm{X}_{1} \mathrm{X}_{2}
\end{aligned}
$$

where $X_{1}$ is $\operatorname{EFI}(\mathrm{V} / \mathrm{cm})$ and $X_{2}$ is retention time (min). $\mathrm{X}_{1} \mathrm{X}_{2}$ is the interaction terms between the two independent factors. $\mathrm{X}_{1}{ }^{2}$ and $\mathrm{X}_{2}{ }^{2}$ are the squared terms.

Table 5 shows the analysis of variance (ANOVA) of the model. Table 5 presents the information in the form of a quadratic model. The significant terms should have $\mathrm{p}-$ value less than 0.05 with the larger of F-test. The p-value of the model is 0.001 and the model F-value is 103.05 indicated that the model is significant. The "lack of fit" in the model should have $\mathrm{p}$-value greater than 0.05 to be non-significant. The analysis in Table 5 present that the linear term $\mathrm{X}_{1}$, the square terms $\mathrm{X}_{1}{ }^{2}, \mathrm{X}_{2}{ }^{2}$ and the interaction term $\mathrm{X}_{1} \mathrm{X}_{2}$ are significant. The linear term $\mathrm{X}_{2}$ is not significant $(\mathrm{P}$-value $>0.05)$ but the term of $\mathrm{X}_{2}$ must be included in the model because it is the main factor of this study and the p-value of linear is less than 0.05. Thus, there are no terms in Eq. (3) should be removed.

The coefficient of determination $\left(\mathrm{R}^{2}\right)$ value of Eq. (3) is 99.42 and adj $\mathrm{R}^{2}$ is $98.46 \%$. It is described that $99.42 \%$ of experiments data are closed to the model for calculation of percentage yield of biodiesel production with electric

\begin{tabular}{|c|c|c|c|c|c|}
\hline Source & $d f$ & $\begin{array}{l}\text { Sum of } \\
\text { Square }\end{array}$ & $\begin{array}{l}\text { Mean } \\
\text { of } \\
\text { Square }\end{array}$ & $\begin{array}{l}\text { F- } \\
\text { Value }\end{array}$ & $\begin{array}{l}\text { P- } \\
\text { Value }\end{array}$ \\
\hline Model & 5 & 2.368 & 0.474 & 103.05 & 0.001 \\
\hline Linear & 2 & 1.457 & 0.728 & 158.44 & 0.001 \\
\hline $\mathrm{X}_{1}$ & 1 & 1.436 & 1.436 & 312.39 & 0 \\
\hline $\mathrm{X}_{2}$ & 1 & 0.021 & 0.021 & 4.5 & $0.124 *$ \\
\hline Square & 2 & 0.714 & 0.357 & 77.67 & 0.003 \\
\hline $\mathrm{X}_{1}^{2}$ & 1 & 0.129 & 0.129 & 28.02 & 0.013 \\
\hline $\mathrm{X}_{2}^{2}$ & 1 & 0.630 & 0.630 & 137.12 & 0.001 \\
\hline $\begin{array}{l}\text { 2-Way } \\
\text { Interaction }\end{array}$ & 1 & 0.193 & 0.193 & 42 & 0.007 \\
\hline $\mathrm{X}_{1} \mathrm{X}_{2}$ & 1 & 0.193 & 0.193 & 42 & 0.007 \\
\hline Error & 3 & 0.014 & 0.005 & & \\
\hline Lack-of-Fit & 2 & 0.002 & 0.001 & 0.1 & 0.913 \\
\hline Pure Error & 1 & 0.011 & 0.011 & & \\
\hline Total & 8 & 2.382 & & & \\
\hline
\end{tabular}
fields.
Table 5. Analysis of variance (ANOVA) of Eq. (3).

*not-significant, P-Value $>0.05$

\begin{tabular}{|c|c|c|c|c|c|}
\hline \multirow[b]{2}{*}{ Run } & \multicolumn{2}{|c|}{ Parameter } & \multicolumn{3}{|c|}{$\%$ Yield } \\
\hline & $\begin{array}{c}\mathrm{X}_{1} \\
(\mathrm{~V} / \mathrm{cm})\end{array}$ & $\begin{array}{c}\mathrm{X}_{2} \\
\mathrm{~min}\end{array}$ & Exp. & Cal. & $\%$ dev. \\
\hline \multirow[t]{2}{*}{1} & 85 & 2 & 98.10 & 98.42 & -0.32 \\
\hline & 85 & 2 & 98.41 & 98.42 & -0.01 \\
\hline \multirow[t]{2}{*}{2} & 170 & 2 & 96.70 & 98.00 & -1.34 \\
\hline & 170 & 2 & 98.96 & 98.00 & 0.97 \\
\hline \multirow[t]{2}{*}{3} & 255 & 2 & 96.50 & 97.03 & -0.55 \\
\hline & 255 & 2 & 98.03 & 97.03 & 1.02 \\
\hline \multirow[t]{2}{*}{4} & 85 & 6 & 97.78 & 97.56 & 0.23 \\
\hline & 85 & 6 & 98.53 & 97.56 & 0.99 \\
\hline \multirow[t]{2}{*}{5} & 170 & 6 & 95.81 & 97.35 & -1.54 \\
\hline & 170 & 6 & 98.57 & 97.35 & 1.23 \\
\hline \multirow[t]{2}{*}{6} & 255 & 6 & 97.14 & 96.60 & 0.55 \\
\hline & 255 & 6 & 98.10 & 96.60 & 1.52 \\
\hline \multirow[t]{2}{*}{7} & 85 & 10 & 96.03 & 97.84 & -1.89 \\
\hline & 85 & 10 & 98.76 & 97.84 & 0.93 \\
\hline \multirow[t]{2}{*}{8} & 170 & 10 & 96.28 & 97.86 & -1.64 \\
\hline & 170 & 10 & 98.75 & 97.86 & 0.90 \\
\hline \multirow[t]{2}{*}{9} & 255 & 10 & 97.46 & 97.33 & 0.13 \\
\hline & 255 & 10 & 98.51 & 97.33 & 1.20 \\
\hline
\end{tabular}

Table 6. Comparison of experiment data and calculation of percentage yields.

Figure 3 shows the percentage yield from experiments and calculation from Eq. (3) (scattered points). The best fit is the solid line. Figure 3 indicates that the model can explain the experiment data of biodiesel yield. Most points are close to the line of best fit. The data in Table 6 shows 
the comparison of percentage yield between experiments data and calculation from Eq. (3).

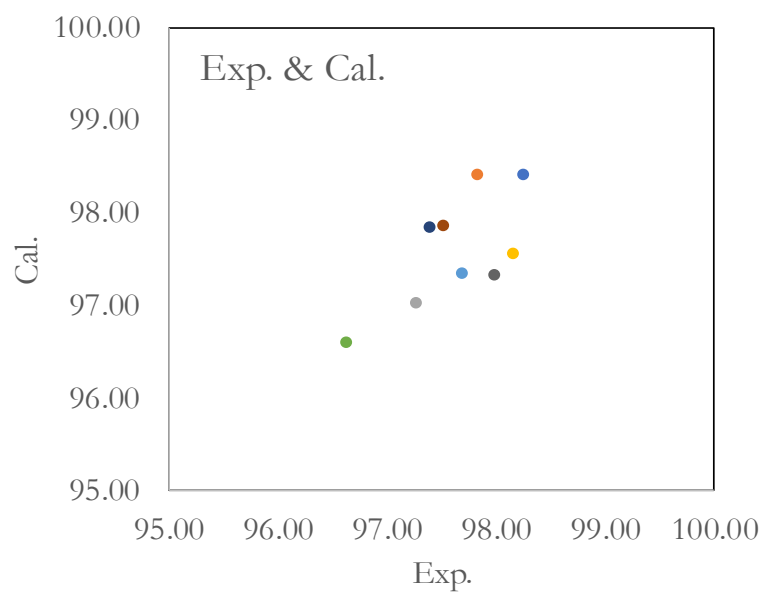

Fig. 3 Experiments and calculation percentage yield of biodiesel.

\subsection{Response Surface Plots}

The yields of biodiesel from palm olein are plotted with EFI and retention time. Figure 4 shows that the best condition is the same designing point: EFI of $85 \mathrm{~V} / \mathrm{cm}$ with $2 \mathrm{~min}$ of retention time. This condition gives a yield of $98.41 \%$ from Eq. (3) and $98.26 \%$ from the experiment. The deviation is $0.16 \%$. The MINITAB introduces the composite desirability of 1.000 which indicates the setting seem to achieve the results for all response.

The three-dimensional (3D) surface plots in Fig. 4 shows that the worst case has a retention time of $5.5 \mathrm{~min}$ and an EFI of $255 \mathrm{~V} / \mathrm{cm}$. This condition provides a yield of $96.59 \%$, as calculated from Eq. (3), and 97.14 and $98.10 \%$ from the experiment. The deviation is 0.55 and $1.52 \%$. The MINITAB presents the composite desirability of 1.000 .

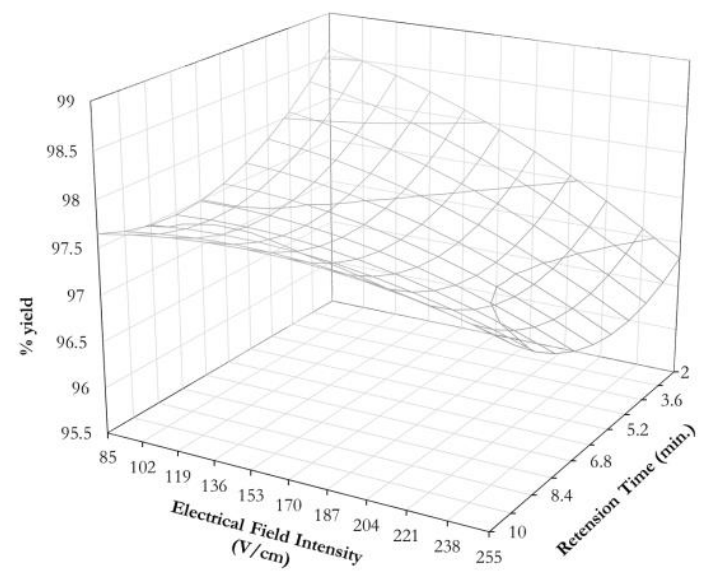

Fig. 4. Response surface plot.

The 3D plots show the effects of EFI and retention time. Lower EFI and lower retention time result in a higher yield, with EFI able to accelerate the reaction rate of biodiesel production as mentioned in Fig. 2.

\section{Conclusion}

The current investigation studies the effect of EFI and retention time on biodiesel production. The study uses an EFI of $85 \mathrm{~V} / \mathrm{cm}, 170 \mathrm{~V} / \mathrm{cm}$, and $255 \mathrm{~V} / \mathrm{cm}$ and retention time of $2 \mathrm{~min}, 6 \mathrm{~min}$, and $10 \mathrm{~min}$. The vegetable oil used is palm olein. The alcohol is $100 \%$ methanol and $\mathrm{KOH}$ at $1 \%$ wt is the catalyst. The molar ratio is $6: 1$. The temperature of the reaction is maintained at $65^{\circ} \mathrm{C}$. This study also compares the yield of biodiesel production from electric fields with that from the conventional reaction.

The results from the experiments show that EFI significantly affects the transesterification reaction rate. The study found that EFI would accelerate the reaction rate of biodiesel production.

This study uses the response surface method (RSM) to examine the optimum condition. The response surface plot shows that the maximum yield condition is from an EFI of $85 \mathrm{~V} / \mathrm{cm}$ and a retention time of $2 \mathrm{~min}$ and give the yield of $98.41 \%$ and deviation is $0.16 \%$. The minimum yield of $96.59 \%$ is from an EFI of $255 \mathrm{~V} / \mathrm{cm}$ and a retention time of $5.5 \mathrm{~min}$.

However, the effects of other factors, for example, of the catalyst, the molar ratio, the temperature, etc. on biodiesel production require future study.

\section{Acknowledgments}

The authors would like to express their gratitude to the Department of Mechanical Engineering, Faculty of Engineering and Industrial Technology, Silpakorn University, Sanam Chandra Palace Campus, and Silpakorn University Research, Innovation and Creative Fund for their laboratory and financial support.

\section{References}

[1] F. Ma and M. A. Hanna, "Biodiesel production: A review," Bioresource Techonology, vol. 70, pp. 1-15, 1999.

[2] I. M. Atadashi, M. K. Aroua, and A. Abdul, "Biodiesel separation and purification: A review," Renewable Energy, vol. 36, pp. 437-443, 2010.

[3] V. Oomsapsin, W. Sriraksa, P. Jamraschai, W. Chuthamthat, and C. Korawich, "Biodiesel production from palm oil," Office of Agricultural Research and Development Region 7, Suratthani Oil Palm Research Center, Thailand, 2005.

[4] S. Rezania, B. Oryani, J. Park, B. Hashemi, K. K. Yadav, E. E. Kwan, J. Hur, and J. Cho, "Review on transesterification of non-edible sources for biodiesel production with a focus on economic aspect, fuel properties and by-product application," Energy Conversion and Management, vol. 201, pp. 115, 2019. 
[5] P. Srivirat, "Effect of pressure on glycerol separation in biodiesel production," in $15^{\text {th }}$ National Conference of Heat and Mass Transfer in Thermal Equipment and Process, 2016.

[6] T. Sappiphatthana, "Important parameters in transesterification for biodiesel production," Ladkrabang Engineering Journal, vol. 32, no. 2, pp. 1-6, 2015.

[7] P. Verma and M. P. Sharma, "Review of process parameters for biodiesel production from different feedstock," Renewable and Sustainable Energy Review, vol. 62, pp. 1063-1071, 2016.

[8] N. Stromberg, H. Eriksson, and A. Saramat, "Determination of phase separation efficiency for biodiesel quality and blending," Fuel, vol. 117, pp. 7478, 2013.

[9] T. Ahmad, M. Danish, P. Kale, B. Gerenew, S. B. Adeloju, M. Nizami, and M. Ayoub, "Optimization of process variables for biodiesel production by transesterification of flaxseed oil and produced biodiesel characterizations," Renewable Energy, vol. 139, pp. 1272-1280, 2019.

[10] Y. H. Tan, M. O. Abdullah, J. Kansedo, N. M. Mubarak, Y. S. Chan, and C. Nolasco-Hipolito, "Biodiesel production from used cooking oil using green solid catalyst derived from calcined fusion waste chicken and fish bones," Renewable Energy, vol. 139, pp. 696-706, 2-19.

[11] K. Nonthawan, N. Paobansuan, and P. Pinit, "Biodiesel production by electric fields," Department of Mechanical Engineering, Faculty of Engineering and Industrial Technology, Silpakorn University, Nakorn Pathom, 2013.

[12] T. Boodkot and P. Khanthong, "Biodiesel production from palm oil by transesterification with electric fields," Department of Mechanical Engineering, Faculty of Engineering and Industrial Technology, Silpakorn University, Nakorn Pathom, 2014.

[13] T. Sangsawang and S. Phetsuwan, "Biodiesel production from animal fat by transesterification with electric fields," in 17th National Conference of Heat and Mass Transfer in Thermal Equipment and Process, Chiangmai, Thailand, 2017, pp. 316-321.

[14] J. F. Wang, C. R. Sun, Y. P. Huo, and R. B. Xu, "Experimental study on the breakup behaviors of charged ethanol droplets in oil," Journal of Engineering Thermophysics, vol. 37, no. 7, pp. 1469-1474, 2016.

[15] T. Sangsawang, W. Kaeprokone, W. Intano, and W. Prasertthongkorn, "Comparison of biodiesel production from used-vegetable oil with electric fields by ethanol and methanol," in 17th National Conference of Heat and Mass Transfer in Thermal Equipment and Process, Chiangmai, Thailand, 2017, pp. 127-132.

[16] N. Nutaman and J. Tiansuwan, "Physical properties comparison of palm biodiesel produced by conventional process and electric field," in 17th National Conference of Heat and Mass Transfer in Thermal Equipment and Process, Lampang, Thailand, 2017, pp. 261-265.

[17] S. Ngammuang, T. Deetayard and T. Kiatsiriroat, "Biodiesel cleaning with dry washing after transesterification," in $16^{\text {th }}$ National Conference of Heat and Mass Transfer in Thermal Equipment and Process, Chiangmai, Thailand, 2016, pp. 304-310.

[18] K. Thippaha, T. Deetayard and T. Kiatsiriroat, "Biodiesel upgrading by catalytic cracking on HZSM-5 catalyst," in $16^{\text {th }}$ National Conference of Heat and Mass Transfer in Thermal Equipment and Process, Chiangmai, Thailand, 2016, pp. 299-303.

[19] S. Thongkumkoon, W. Kiatkittipong, U. W. Hartley, N. Laosiripojana and P. Daorattanachai, "Catalytic activity of trimetallic sulfide $\mathrm{Re}-\mathrm{Ni}-\mathrm{Mo} / \boldsymbol{\gamma}-\mathrm{Al}_{2} \mathrm{O}_{3}$ toward deoxygenation of palm feedstocks," Renewable Energy, vol. 140, pp. 111-123, 2019. 
Thibordin Sangsawang, Ph.D., was born in Uttaradit. He recieved his Bechelor Degree in Mechanical Engineering, Chiang Mai University in 1997. He completed the Master Degree and Ph.D. in Thermal Technolgoy from KMUTT in 2010. His topic was engine simulation with biodiesel. Now he is assistant professor in the Department of Mechanical Engineering, Faculty of Engineering and Industrial Technology, Silpakorn University Sanam Chandra Palace Campus, Thailand.

His fields of expertise are about diesel engine, biodiesel and renewable energy. He is the member of Mechanical Engineering Commitee, the Engineering Institute of Thailand for 2016 - 2018. He is a member of ASRAE since 2017.

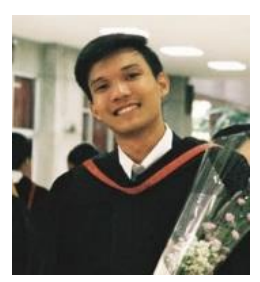

Nirat Rongrat was born in Phattalung, Thailand in 1997. He finished his high school certificage from Phattalung School, Phattalung, Thailand. He received his Bachelor Degree in Mechanical Engineering, Silpakorn University in 2018. Now he works as production engineer in Khao C.P. Co. Ltd. Since October 2019.

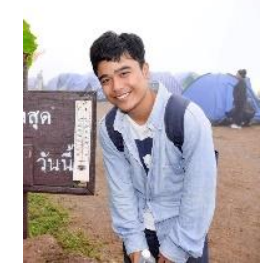

Aphishat Yothayuth was born in Pathumthani, Thailand, 1996. He completed his high school certificate from Pathumwilai School. Pathumthani, Thailand. He received his Bachelor Degree in Mechanical Engineering, Silpakorn University in 2018. Now he works as product engineering in Khao C.P. Co. Ltd. Since July 2019. 